\section{TPPeriodica Polytechnica Civil Engineering}

OnlineFirst (2018) paper 11284

https://doi.org/10.3311/PPci.11284

Creative Commons Attribution (i)

\title{
Durability Assessment of Clay-Bearing Soft Rocks By Using New Decay Index
}

\author{
Mojtaba Heidari $^{* 1}$, Aliakbar Momeni ${ }^{2}$, and Yazdan Mohebbi ${ }^{1}$
}

RESEARCH ARTICLE

Received 19 July 2017; Revised 29 October 2017; Accepted 30 November 2017

\begin{abstract}
Clay-bearing rocks are known as most important problematic weak rocks. Due to the importance of disintegration of claybearing rocks in engineering projects, several simple test methods have been proposed to assess durability of these rocks. In this study, a comprehensive research program was conducted on twenty different clay-bearing rocks to assess their disintegration characteristics under laboratory conditions. In order to carry out the research, at the first step some physical and mechanical properties of the studied rocks were measured. After that, three durability test methods were employed. These tests include the standard slake durability test to obtain index durability ( $\left(\mathrm{d}_{2}\right)$, slake durability test with sieving the remained materials in drum to obtain disintegration ratio (DR) and new time series slake durability test to obtain decay index (DI). The results of this research indicated that for most of samples, using the standardized slake durability index test ( $\left.\mathrm{Id}_{2}\right)$ may not be adequate to understand the disintegration characteristics of clay-bearing rocks and shows overestimated values. The new decay index (DI) has overcome the most limitations of the standard slake durability test and clearly will realize deterioration potential of clay bearing rocks. Finally, based on the results of decay index a new durability classification was proposed.
\end{abstract}

\section{Keywords}

clay-bearing rocks; decay index; disintegration ratio, slake durability

\footnotetext{
1 Department of Geology

Faculty of Sciences,

Bu-Ali Sina University

65175-38695 Mahdieh Ave. Hamedan-Iran

2 Faculty of Erath Sciences,

Shahrood University of Technology,

Shahrood, Iran

* Corresponding author, email: heidarim_enggeol@yahoo.com
}

\section{Introduction}

Clay-bearing rocks are the most common type of rocks which have covered land surface (about one-third of the total land surface) [1]. So, most of engineering projects have to be in relation with these rocks. Decay of clay-bearing rocks can greatly affect the engineering properties of clay-bearing rocks within engineering timescales, and may include rapid change in durability and strengths from rock-like properties to soil-like in slaking states. The better possibilities to determine future behavior of rock may allow for more projects hazard analysis and narrowing the gap between rock engineering and civil engineering.

Because of clay-bearing durability importance, many researchers have focused on degradation behavior of these rocks [1-3]. Determination of clay bearing rocks decay for earthwork construction is typically based on its slaking durability. Three of the more popular slaking tests are the jar slake test [4], slake index test [5], and slake durability test [6]. A major focus was on determining the applicability of the slake durability test. The slake durability test is used widely for evaluation of slaking behavior of rocks as a result of wettingdrying processes [7-13]. However, due to mechanical breaks occurring during the test, immersion of samples in water for only $10 \mathrm{~min}$ and the assumption that fragments larger than 2 $\mathrm{mm}$ are durable, the slake durability test has some limitations [14]. Many researchers have tried to overcome these limitations. For improving time limitation Taylor [14] and Gokceoglu et al. [9] suggested that a 3 and 4 cycle test is more reliable test that 2 cycle test to determine durability. A valuable work was done by Erguler and Shakoor [15] to overcome the problem with standard test mesh size $(2 \mathrm{~mm})$. They have proposed a new parameter called "disintegration ratio" based on grain size distribution curve of slaked material. A comprehensive work which considers all of standard test limitations was neglected up to now. In the recent decade, many researchers have focused on improving rock durability assessment methods. Gautam and Shahkoor [16] have evaluated slaking behavior of clay-bearing rocks during a one-year exposure to natural climatic conditions. In other work, they [17] have compared the laboratory slaking behavior of common clay-bearing rocks 
in five cycles to their slaking behavior under natural climatic conditions during a 1-year. They founded that standard laboratory slaking durability test (Id2) underestimates the field durability of clay-bearing rocks. Ricon et al. [18] believed that laboratory test on fresh sample overestimate durability behavior of clay-bearing rocks and used microtremor $\mathrm{H} / \mathrm{V}$ spectral ratio and image entropy techniques to quantify the insitue degrees of disintegration. Heidari et al. [19] have assessed suitability of the static and dynamic standard slaking tests for using durability assessment of clay-bearing rocks. Their results showed that the materials retained in the $2 \mathrm{~mm}$ mesh drum consists of disintegrated particles varying in diameter and they proposed a sieve analysis of the materials retained. To better measurement of durability behavior. Nadesha et al. [20] evaluates chemical, mineralogical and textural properties of Kope mudstones to determine why it is less durable. They have found that fabric types have considerable effect on the mudstone durability.

The basic idea behind this research is answering the question that how reliable assessment of clay bearing rocks durability will be done. Therefore, this paper presents an experimental investigation on data from a series of modified slake durability tests which considering the effects of test duration time and disintegrated fragments size. From these data, a new durability index called the Decay Index (DI) was developed. This index represents the rate of deterioration of clay bearing rocks. The main aim of the present study was to compare between the $\mathrm{Id}_{2}$ and DI in predicting of the slaking behavior of clay-bearing rocks.

\section{Selection of samples and testing procedures}

Many block samples from 20 different clay-bearing rock types were collected from across the Iran (Fig. 1). Then 300 specimens (cores and rock lumps) were prepared from them for performing physical and mechanical tests. The samples had been stored in plastic buckets covered with airtight lids to preserve natural moisture content and to prevent any deterioration due to atmospheric exposure. The rock code, description, lithology, geologic name, geologic age, and site description of each rock type are listed in Table 1. Tests on the samples were performed at the Rock Mechanics Laboratory of the Engineering Geology Department of Bu-Ali Sina University in Hamedan, Iran. The following physical and mechanical properties of rock samples were measured in accordance with the standard procedures of the [21]: dry density, porosity, water absorption and second slake durability index. For measuring Atterberg limits (liquid limit and plastic limit), rock samples were disaggregated by soaking in water for 14 days and then pieces of material remaining were gently broken down with a pestle and mortar. The disaggregated material was sieved through a British Standard $0.425 \mathrm{~mm}$ sieve, the material passing being used to determine the plastic and liquid limits. Point-load index tests were performed following the recommendations of ISRM [22].

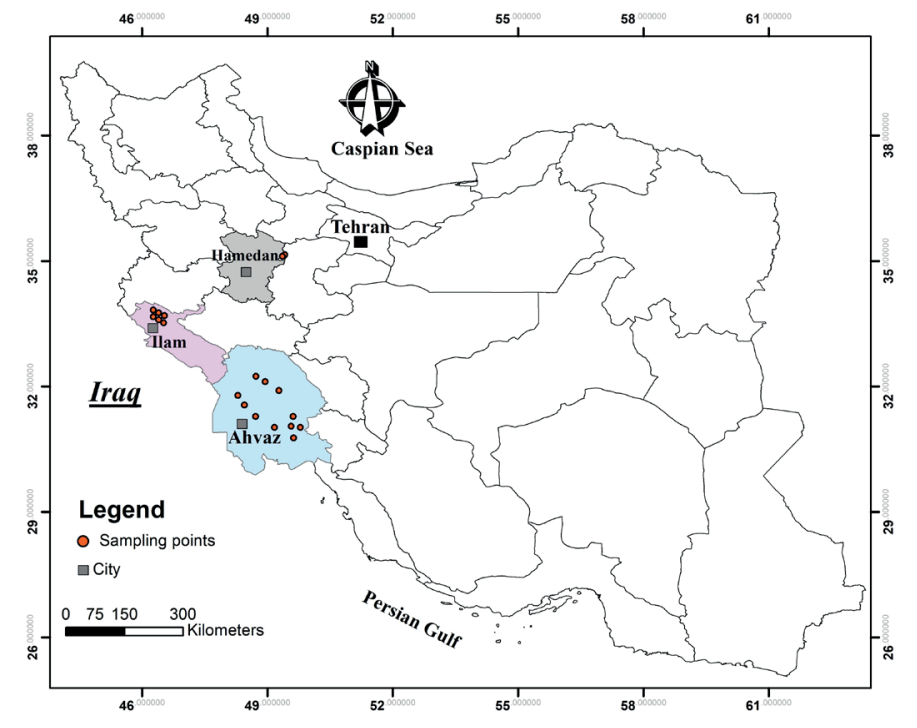

Fig. 1 Location map for the sampling sites in the west of Iran

Carbonate percentages of the samples were determined by calcimetery test. The test procedure was applied according to ASTM C97-02 [23]. The slake durability test was carried out in accordance with ASTM method D-4644 [21]. This procedure is repeated, and the $\mathrm{Id} 2$ is computed as the ratio of the dry weight remaining in the drum to the initial dry weight, expressed as a percentage. The slaking behavior of clay-bearing rocks cannot be described adequately using a single aperture, such as the $2-\mathrm{mm}$ mesh drum used in the standardized slake durability index test. Therefore, the fragment size distribution approach was used in this study to better define the slaking characteristics of the rocks tested. In order to minimize this limitation, the durability test was conducted using a set of nested stainless steel drums of diameters 140, 180, 250, and $300 \mathrm{~mm}$, constructed of woven-wire cloth of 25.4, 12.7, 6.35 , and $2.0 \mathrm{~mm}$ mesh (innermost to outermost). Each cylindrical drum is $100 \mathrm{~mm}$ long. The main feature of the trough and drum assembly is illustrated in Fig. 2. The two end plates are rigid, with one being removable. Because the exterior of the meshes and the interior of the drums cannot be obstructed by supports, the strength of the assembly is provided by a trough that supports the drums horizontally, enabling the drums to rotate freely about a common axle and ensuring that the shape of the drums is retained during use. The trough can be filled with water to a level of $170 \mathrm{~mm}$ below the axle, with a minimum clearance of $20 \mathrm{~mm}$ between the trough and the bottom of the last mesh. The drums are rotated by a motor capable of maintaining a speed of $20 \mathrm{rpm}$ for a period of 10 minutes. A digital timer automatically stops the motor after a preset time. Rotation of the drums sieves the rock lumps, separating them into size fractions: oversized grains are trapped above the drum screens, while undersized grains pass through the screens. Following the rotation period, the drums are extracted from the trough and the drum lids are removed. The retained rock samples are then dried to a constant weight at $105^{\circ} \mathrm{C}$ and 
weighed, and the weight of the retained pieces is recorded. The percentage retained is calculated for each drum by dividing the dry weight retained in each drum by the weight of the original dry samples. This separation of the samples into size fractions enables particle size distributions to be determined. After wetting-drying cycle, the degree of disintegration is indicated by the distribution of grain sizes. Slake-durability testing procedures were investigated and compared, using the procedure described above with certain modifications regarding the time interval (The samples were rotated in the wire drum for 10, 30, 60 , and $120 \mathrm{~min}$, respectively).
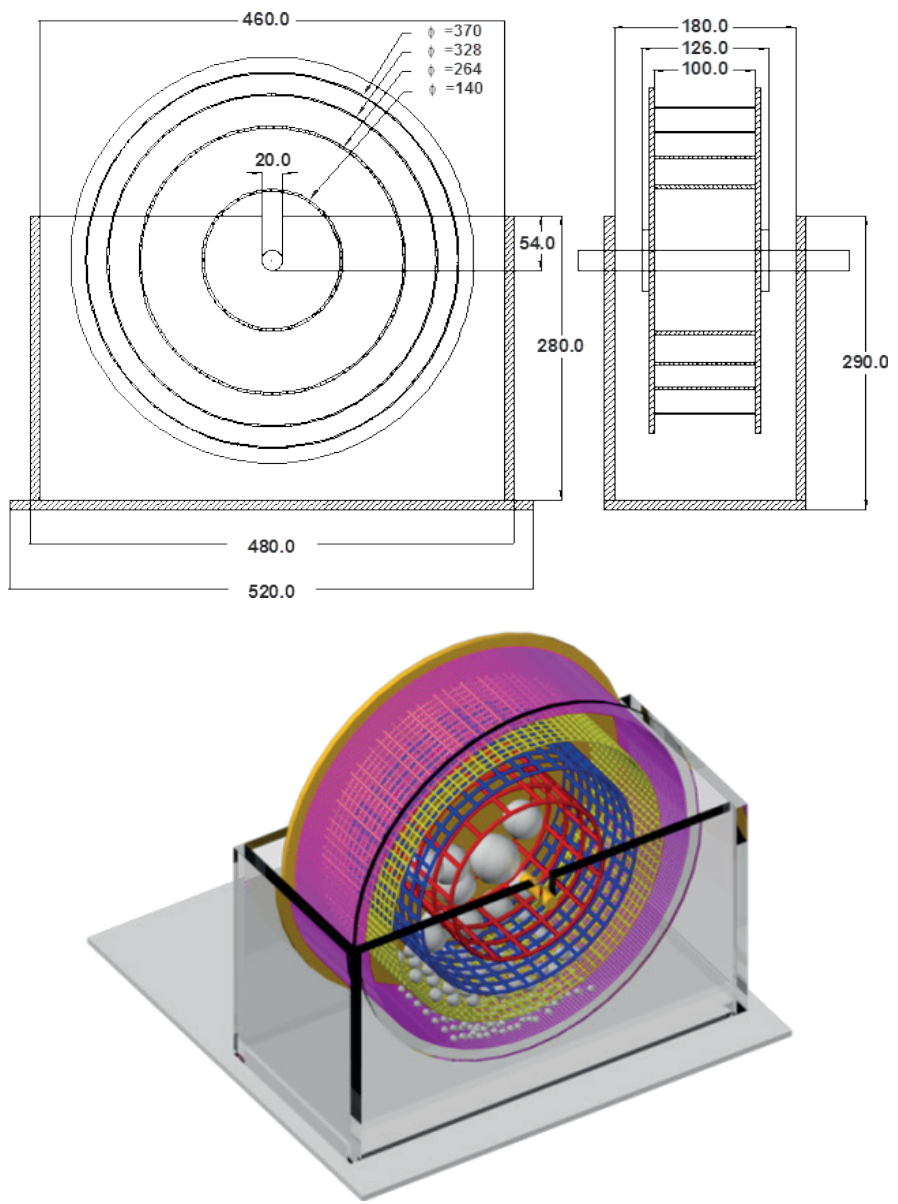

Fig. 2 Nested drum apparatus shown from the front, the side and general view. Ø: Drums diameter (mm).

\section{Results and discussion}

\subsection{Index properties}

For the purpose of better understanding the effect of physical and mechanical and chemical properties on disintegration characteristics, some of these properties were determined for all rock samples. The tests results are summarized in Table 2. The calcium carbonate content ranges from $27 \%$ to $.65 \%$. High values of index durability from rock samples such as P-3 usually correspond to calcareous rocks with high carbonate content. The rock material had low to high plasticity. The liquid limit, ranged from about $9 \%$ to $49.2 \%$ and the plastic index ranged from 2 to $27.35 \%$. The sample numbers P-1, P-2, P-3, P-4, G-2, Ag-6, Ag-10 and Ag-11 have lower porosity $(\mathrm{n}<8.32 \%)$ and lower water absorption (IV < 9.1). The density of rock samples varies from $1.98 \mathrm{~g} / \mathrm{cm}^{3}$ to $2.67 \mathrm{~g} / \mathrm{cm}^{3}$. Among the studied samples, Ag-5 sample has the lowest mean value of dry density and the highest mean porosity about $1.98 \mathrm{~g} / \mathrm{cm}^{3}$ and $28.67 \%$, respectively. High porosity and high clay minerals content of Ag-5 leads to the lowest point load strength and slake durability index for this samples. In contrast, Sample P-3 with the lowest water absorption index shows the highest point load strength and slake durability index. A close inspection of Table 2 indicates that with increasing porosity, water absorption index, and clay minerals content both point load strength and slake durability index increased. Also, it can be concluded that between these physico-mechanical and chemical characteristics is a reliable relationship.

The standard $\operatorname{Id}_{2}$ value ranges from $61.88 \%$ to $99.35 \%$ of the original dried weight. According gamble's classification (Table 2) rock samples can be divided into four distinctive groups designated as very high, high, medium-high and medium durability. Regardless of the rock types, the Table 2 indicates that most of the samples can be classified as highly durable rocks. The slake durability test results show that the rock samples disintegrated into fragments of varying sizes after each time cycle and a great number of which did not pass through the $2 \mathrm{~mm}$ mesh of the drum. This was already introduced by Erguler and Shakoor [15]. A similar behavior has been seen in the nature for degradation pattern of these rocks (Fig. 3). Clay-bearing rocks are quickly deteriorated to fragments which are mostly larger than $2 \mathrm{~mm}$ when they expose under natural atmospheric conditions. Sensitivity to atmospheric exposure and low durability of them lead to have hilly morphology and mostly for achievement of sound clay-bearing sample removing more than $50 \mathrm{~cm}$ overburden is necessary. That is the main disadvantage of durability assessing by slake durability test with just $2 \mathrm{~mm}$ mesh.

Moon and Beattie [7], Erguler [24], and Erguler and Ulusay [13] also showed that rock materials break into fragments of varying sizes during the second cycle of the slake durability test, and that the fragments are much larger than the mesh of the drum $(2 \mathrm{~mm})$. The large fragments that are retained in the drum are therefore classified as durable materials. The slake durability test which was proposed by Franklin and Chandra [6] does not offer an acceptable measure of the durability of clay-bearing rocks. The standard test requires grain size analysis, which is a laborious procedure requiring a set of sieves, to describe the disintegration characteristics of the rocks after each time cycle. The authors have considered that durability assessment by using a set of nested drums with mesh sizes of 25.4, 12.7, 6.35, and $2.0 \mathrm{~mm}$ provides a better indicator of the slake durability of rock samples. The modified test is an application of the method already introduced by Erguler and Shakoor [15], who suggested that the DR should be used to define the grain size distributions, as follows: 


$$
D R=A C / A T
$$

Where $A C$ is the area under the distribution curve for any fragment size and $A T$ is the total area encompassing the range of fragment size distributions. By calculating the area under the distribution curve for any grain size $(A C)$ and the total area encompassing all grain size distribution curves $(A T)$ of the tested samples, the $D R$ was determined after the second of wetting-drying cycles with 10 minutes rotation. The index ranges from 0 to 1 , which low values indicating less durable rock and high values indicating high durability.

\begin{tabular}{|c|c|c|c|}
\hline Formation & Rock code & Rock type & Location of sampling \\
\hline \multirow{4}{*}{$\begin{array}{l}\text { Qom } \\
\text { (Oligo } \\
\text { Miocene) }\end{array}$} & S-1 & Marl & Tajarak \\
\hline & $\mathrm{S}-2$ & Marl & Tajarak \\
\hline & S-3 & Marl & Tajarak \\
\hline & P-1 & Sandy Marl & Ilam \\
\hline \multirow{3}{*}{$\begin{array}{l}\text { Pabdeh } \\
\text { (Paleocene) }\end{array}$} & P-2 & Marl & Ilam \\
\hline & P-3 & Marly Limestone & Ilam \\
\hline & P-4 & Sandy Limey Marl & Ilam \\
\hline \multirow{6}{*}{$\begin{array}{l}\text { Gurpi } \\
\text { (Cretaceous) }\end{array}$} & G-1 & Marl & Ilam \\
\hline & G-2 & Limey Marl & Ilam \\
\hline & Ag-1 & Marl & Rag Sefid \\
\hline & $\mathrm{Ag}-2$ & Marl & Mashrahat \\
\hline & $\mathrm{Ag}-3$ & Clayey Siltstone & Krit Camp \\
\hline & Ag-4 & Clayey Siltstone & Hasirabad \\
\hline \multirow{7}{*}{$\begin{array}{l}\text { Aghajari } \\
\text { (Upper } \\
\text { Miocene } \\
\text { Pliocene) }\end{array}$} & $\mathrm{Ag}-5$ & Marl & Omoddis \\
\hline & Ag-6 & Clayey Siltstone & Haftgel \\
\hline & $\mathrm{Ag}-7$ & Marl & Naftsefid \\
\hline & Ag-8 & Clayey Siltstone & Tak Takab \\
\hline & Ag-9 & Clayey Siltstone & Tembi \\
\hline & Ag-10 & Clayey Siltstone & Masjedsolyman \\
\hline & Ag-11 & Clayey Siltstone & Gotvand \\
\hline
\end{tabular}

Table 2 presents the $\mathrm{DR}_{2}$ data for all rock samples. The value of DR after second cycle varies from 0.48 to 0.99 . As seen in Table 2, some of the clay-bearing rocks experience significant disintegration after second wetting-drying cycles. This type of breakdown has been referred to as body slaking. Table 2 shows that the samples of, S-2, S-3, P-2, G-1, Ag-1, Ag-3, Ag-6, Ag-7 and Ag-8 $\left(\mathrm{DR}_{2}<0.85\right)$, were moderately and Ag-2 and Ag-5 $\left(\mathrm{DR}_{2}<0.50\right)$ were hardly disintegrated in the slake durability test while some portions of the samples were retained within the $2 \mathrm{~mm}$ drum after the second wetting-drying cycle. Comparing the results of $\mathrm{Id}_{2}$ and $\mathrm{DR}_{2}$ for the studied rocks indicated that second cycle slake durability test overestimates the durability behavior of these rocks especially for samples $\mathrm{S}-2, \mathrm{~S}-3$, G-1, Ag-1 to Ag-3, Ag-5, Ag-6, Ag-8, and Ag-9.

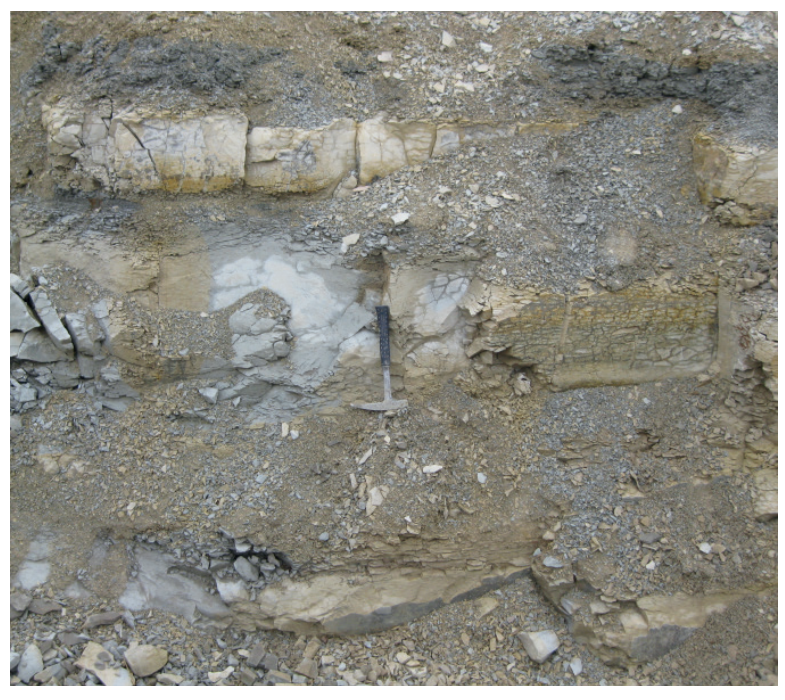

Fig. 3 Disintegration of marlstone in to different grain size in the nature

\subsection{Decay Index (DI)}

The first step in proposing a quantitative index is to determine the parameters of clay-bearing rocks relating to slake durability. From an engineering geological standpoint, indices based on key properties generally have more applicability and are also usually much simpler and less time-consuming to measure. Therefore, here we develop a quantitative index using combinations of the Area Ratio (AR) and water absorption (IV). $\mathrm{AR}$ is the rate of deterioration for each sample, as reflected in the area under the DR - time curve that is used as the basis for developing a new reliable durability index (Fig. 4).
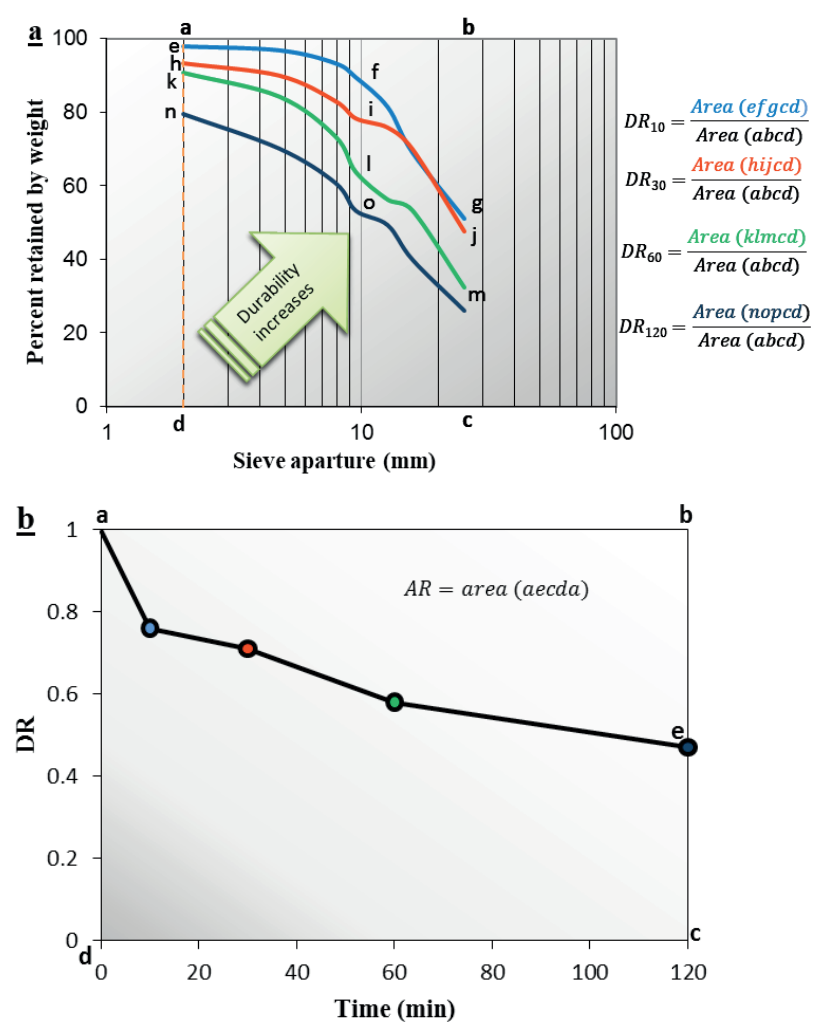

Fig. 4 (a) Grain size distribution curves for G-1sample after different time wetting and drying cycles and (b) DR- time curve of G-1 sample which was used for calculation of AR 
Table 2 The average testing data of rock samples

\begin{tabular}{|c|c|c|c|c|c|c|c|c|c|c|}
\hline $\mathrm{RC}$ & $\mathrm{Is}_{50}(\mathrm{MPa})$ & $\mathrm{CaCO}^{3}(\%)$ & Clay (\%) & $\mathrm{PI}(\%)$ & LL(\%) & $\mathrm{n}(\%)$ & Iv $(\%)$ & $\gamma_{\mathrm{d}}\left(\mathrm{gr} / \mathrm{cm}^{3}\right)$ & $\mathrm{Id}_{2}(\%)$ & $\mathrm{DR}_{2}(\%)$ \\
\hline S-1 & 1.61 & 27.0 & 41.30 & 9.3 & 27.5 & 16.43 & 13.96 & 2.48 & 94.06 & 0.90 \\
\hline S-2 & 1.12 & 42.0 & 38.70 & 13.3 & 30.5 & 12.45 & 10.57 & 2.47 & 95.53 & 0.77 \\
\hline S-3 & 1.60 & 29.0 & 49.40 & 18 & 39.2 & 25.02 & 17.68 & 2.45 & 85.92 & 0.76 \\
\hline P-1 & 2.25 & 52.0 & 26.90 & 10.2 & 23.6 & 6.83 & 4.32 & 2.54 & 97.50 & 0.94 \\
\hline P-2 & 1.92 & 55.0 & 39.70 & 9.3 & 24.5 & 6.59 & 8.59 & 2.63 & 85.87 & 0.84 \\
\hline P-3 & 3.12 & 65.0 & 26.50 & 8.1 & 20.1 & 5.50 & 3.11 & 2.67 & 99.35 & 0.99 \\
\hline P-4 & 2.83 & 58.0 & 38.80 & 11.8 & 24.6 & 3.17 & 5.46 & 2.61 & 98.40 & 0.95 \\
\hline G-1 & 1.72 & 31.0 & 38.90 & 14.7 & 30.8 & 13.10 & 11.45 & 2.47 & 93.82 & 0.69 \\
\hline G-2 & 2.08 & 55.0 & 29.60 & 12.80 & 25.40 & 7.91 & 3.76 & 2.56 & 98.87 & 0.94 \\
\hline Ag-1 & 0.88 & 30.50 & 48.2 & 22.03 & 49.00 & 22.78 & 27 & 2.10 & 70.62 & 0.52 \\
\hline $\mathrm{Ag}-2$ & 0.47 & 36.00 & 47.2 & 11.92 & 32.56 & 22.05 & 22 & 2.10 & 61.88 & 0.48 \\
\hline Ag-3 & 0.70 & 43.50 & 17.2 & 3.22 & 24.70 & 19.4 & 21 & 2.20 & 84.21 & 0.61 \\
\hline $\mathrm{Ag}-4$ & 0.71 & 33.50 & 14.6 & 3.93 & 28.00 & 16.67 & 19.78 & 2.29 & 95.43 & 0.90 \\
\hline $\mathrm{Ag}-5$ & 0.32 & 28.00 & 48.8 & 19.79 & 47.60 & 28.67 & 28 & 1.98 & 61.61 & 0.48 \\
\hline Ag-6 & 1.19 & 38.00 & 8.6 & 2 & 12 & 7.28 & 9.1 & 2.48 & 98.04 & 0.80 \\
\hline Ag-7 & 1.87 & 44.00 & 21.5 & 7.86 & 28.85 & 10.52 & 7.7 & 2.21 & 98.46 & 0.94 \\
\hline Ag- 8 & 1.01 & 45.50 & 10.5 & 27.35 & 31.48 & 16.76 & 18.5 & 2.17 & 94.24 & 0.82 \\
\hline Ag-9 & 0.87 & 42.00 & 8.3 & 5.76 & 28.20 & 11.63 & 17.3 & 2.37 & 90.42 & 0.84 \\
\hline Ag-10 & 2.89 & 38.50 & 7 & 3 & 9 & 5.68 & 5.09 & 2.51 & 98.69 & 0.95 \\
\hline Ag-11 & 2.79 & 36.50 & 15.5 & 3.89 & 25.16 & 8.32 & 7.04 & 2.50 & 98.72 & 0.97 \\
\hline
\end{tabular}

RC: Rock code, Is $_{50}$ : Point load index; PI: Plasticity index; LL: Liquid Limit; n: Porosity; Iv: Water absorption; $\gamma_{\mathrm{d}}$ : Dry density, Id ${ }_{2}$ : Second slake durability index, $\mathrm{DR}_{2}$ : Second cycle disintegration ratio

Table 3 Summary of values of the slaking indices and disintegration ratio obtained from various time cycle tests

\begin{tabular}{|c|c|c|c|c|c|c|c|c|}
\hline \multirow{2}{*}{ Sample number } & \multicolumn{2}{|c|}{$10 \mathrm{~min}$} & \multicolumn{2}{|c|}{$30 \mathrm{~min}$} & \multicolumn{2}{|c|}{$60 \mathrm{~min}$} & \multicolumn{2}{|c|}{$120 \mathrm{~min}$} \\
\hline & $\mathrm{Id}_{10}$ & $\mathrm{DR}_{10}$ & $\mathrm{Id}_{30}$ & $\mathrm{DR}_{30}$ & $\mathrm{Id}_{60}$ & $\mathrm{DR}_{60}$ & $\mathrm{Id}_{120}$ & $\mathrm{DR}_{120}$ \\
\hline $\mathrm{S}-1$ & 97.34 & 0.96 & 88.16 & 0.87 & 81.15 & 0.81 & 54.46 & 0.54 \\
\hline $\mathrm{S}-2$ & 97.54 & 0.80 & 86.93 & 0.65 & 79.14 & 0.77 & 56.82 & 0.55 \\
\hline $\mathrm{S}-3$ & 92.99 & 0.83 & 77.45 & 0.53 & 39.42 & 0.34 & 19.79 & 0.16 \\
\hline $\mathrm{P}-1$ & 98.82 & 0.97 & 96.09 & 0.94 & 95.21 & 0.91 & 77.71 & 0.74 \\
\hline $\mathrm{P}-2$ & 93.15 & 0.89 & 80.67 & 0.75 & 69.58 & 0.66 & 56.09 & 0.49 \\
\hline $\mathrm{P}-3$ & 99.69 & 0.99 & 99.45 & 0.99 & 99.16 & 0.99 & 98.11 & 0.98 \\
\hline $\mathrm{P}-4$ & 99.51 & 0.97 & 99.11 & 0.96 & 97.12 & 0.95 & 90.69 & 0.89 \\
\hline $\mathrm{G}-1$ & 97.87 & 0.76 & 93.25 & 0.71 & 90.65 & 0.58 & 79.35 & 0.47 \\
\hline $\mathrm{G}-2$ & 99.53 & 0.99 & 99.21 & 0.98 & 96.30 & 0.89 & 94.56 & 0.86 \\
\hline Ag-1 & 86.83 & 0.78 & 60.79 & 0.48 & 28.29 & 0.2 & 0 & 0 \\
\hline $\mathrm{Ag}-2$ & 89.89 & 0.8 & 68.27 & 0.55 & 49.56 & 0.4 & 3.25 & 0 \\
\hline Ag-3 & 93.5 & 0.85 & 75.43 & 0.66 & 32.36 & 0.22 & 1.06 & 0 \\
\hline $\mathrm{Ag}-4$ & 97.96 & 0.94 & 95.04 & 0.9 & 81.96 & 0.69 & 43.84 & 0.28 \\
\hline Ag-5 & 89.92 & 0.81 & 61.85 & 0.5 & 13.51 & 0.05 & 0 & 0 \\
\hline Ag-6 & 98.94 & 0.97 & 96.63 & 0.88 & 90.37 & 0.77 & 74.51 & 0.62 \\
\hline Ag-7 & 98.92 & 0.98 & 97.33 & 0.94 & 93.51 & 0.9 & 85.33 & 0.84 \\
\hline Ag-8 & 96.95 & 0.94 & 89.81 & 0.8 & 70.8 & 0.63 & 29.66 & 0.19 \\
\hline Ag-9 & 96.87 & 0.94 & 91.67 & 0.84 & 68.84 & 0.67 & 33.92 & 0.23 \\
\hline Ag-10 & 99.25 & 0.99 & 98.59 & 0.97 & 96.33 & 0.94 & 91.54 & 0.89 \\
\hline Ag-11 & 99.18 & 0.99 & 97.56 & 0.96 & 93.69 & 0.92 & 86.47 & 0.83 \\
\hline
\end{tabular}


It is specifically observed that sample numbers P-3, G-2, Ag-6, Ag-7 and Ag-10 with a high percentage of material retained in the 10-minute cycle show a lower loss of mass during the subsequent cycle times. These samples appear to be hard and more durable. Conversely, the rock samples (S-3, P-2, G-1, Ag-1, Ag-2, Ag-3, Ag-4, Ag-5, Ag-8 and Ag-9) that have a low percentage of material retained in the $10-\mathrm{min}$ ute cycle show a greater loss of mass during the subsequent cycle times. This behavior tends to correspond to the softer, less durable samples. Although the DR corresponding to the 10-minute cycle appears to give an indication of the durability but the difficulty arises due to the dependency of the simulated weathering process on the exposure time of the weak rock to environmental factors.

The concern for the conventional test is whether or not the 10 -minute cycle is representative of the time that weak rocks are exposed to the weathering process in field. In this study, the durability test was modified by using only one wetting and drying cycle. The samples were rotated in the wire drum for 10, 30, 60, and $120 \mathrm{~min}$, respectively. Thus, these modified slake durability indices $\left(\mathrm{Id}_{\text {time }}\right.$ and $\left.\mathrm{DR}_{\text {time }}\right)$ values for a given time cycles were calculated. Indices obtained from slake durability tests in interval time $\left(\mathrm{DR}_{\text {time }}\right.$ and $\left.\mathrm{Id}_{\text {time }}\right)$ are summarized and compared in Table 3.

Test results show that generally, all of clay-bearing rocks exhibit a wide variation in their $\mathrm{DR}_{\text {time }}$ values. $\mathrm{DR}_{\text {time }}$ decreases with the increasing cycle duration. For better description of rock samples durability, $\mathrm{DR}_{\text {time }}$ values were determined at interval times of 10, 30, 60 and 120 minutes and plotted versus the interval time. The area under curve (AR) was calculated by joining the plotted points into a polygon figure (Fig. 4b). The area under this curve shows the amount and rate of deterioration potential for each rock sample from its initial state. The AR ranges from 0 to 120 . Highly durable rock has a greater $\mathrm{AR}$ in such a plot (e.g. rock sample number "P-3" with $\mathrm{DR}_{10}=$ $\mathrm{DR}_{30}=\mathrm{DR}_{60}=0.99$ and $\mathrm{DR}_{120}=0.98$, has $\mathrm{AR}$ of 118.86) than less durable rock (e.g. rock sample number "Ag-5" with $\mathrm{DR}_{10}=$ $0.81, \mathrm{DR}_{30}=0.50, \mathrm{DR}_{60}=0.05$ and $\mathrm{DR}_{120}=0.0$, has AR of 31.9). Low values indicating less durable and faster rates of deterioration and high values indicating relatively higher durability and slower rates of deterioration. Calculated AR for all samples are summarized and compared in Table 4.

Besides, it is well known that for clay-bearing rocks physico-chemical and mechanical effects of rock-water interaction are important causes for deformation and deterioration of rocks. The water absorption values varied significantly among rock samples and increases with increasing the number of microcracks and porosity increases. Clay mineral percentage and clay mineral types presented in rock is one of the most important parameters affecting water absorption performances. These observations are consistent with the results of Irfan and Dearman [25]. Water absorption index has both direct and indirect effects on most of the physical properties of clay bearing rocks and is, therefore, considered the most important clay bearing rock parameter [26-28]. The calculated values of water absorption of the studied rocks are reported in Table 2. The water absorption value for the rock samples varies from 3.11 to 29 for samples P-3 and Ag-5, respectively. Water absorption index is considered to be the best parameter for representation of changes in durability behavior. Therefore, a quantitative index was developed by combining AR and water absorption. To fully describe the slake-durability characteristics of a clay-bearing rock samples, the proposed index was defined as:

$$
D I=A R / I V
$$

In which, $D I$ is decay index, $A R$ : area under the $\mathrm{DR}_{\text {time }}$-time curve and $I V$ is water absorption percent value. By using durability decay index, slake durability of rock samples was better distinguishable. Highly durable rock has a greater area under the curve ( $\mathrm{DR}_{\text {time }}$ * minutes) but conversely as can be seen from Table 2 with one exception (sample number P-2) the rocks with low durability tend to have high water absorption values. In other words, high water absorption values indicate less durable rock materials. The rock samples were ranked according to descending values of decay indices.

Table 4 Results of the measured area ratio and decay index for the studied rocks

\begin{tabular}{lcc}
\hline Sample number & AR & DI \\
\hline S-1 & 94.2 & 674.78 \\
S-2 & 85 & 804.16 \\
S-3 & 51.34 & 290.38 \\
P-1 & 106.87 & 2474 \\
P-2 & 77.57 & 903 \\
P-3 & 118.86 & 3822 \\
P-4 & 113.66 & 2082 \\
G-1 & 75.27 & 657 \\
G-2 & 110.78 & 2946 \\
Ag-1 & 37.7 & 140 \\
Ag-2 & 48.75 & 222 \\
Ag-3 & 44.15 & 210 \\
Ag-4 & 81.05 & 410 \\
Ag-5 & 31.9 & 114 \\
Ag-6 & 94.8 & 1042 \\
Ag-7 & 108.9 & 1414 \\
Ag-8 & 73.15 & 395 \\
Ag-9 & 77.15 & 446 \\
Ag-10 & 113.1 & 2222 \\
Ag-11 & & 1565 \\
\hline & & \\
\hline
\end{tabular}

From Table 4, it can be seen that the rock samples in this study have wide range of DI values. In other words, the DI can be used successfully to distinguish between different durability behaviors. In order to better describe the durability 
behavior of clay-bearing rocks a classification system based on DI was proposed. As is shown in Table 5, the new durability classification has five categories for durability including very low (DI $=0-100)$, low $(\mathrm{DI}=100-500$, moderately $(\mathrm{DI}=$ 500-1500), high (DI = 1500-3000), and very high (DI > 3000). The decay indices of the samples tested vary from 114 to 3822 . From Table 4, it can be seen that very low durability was not found among the studied rocks. $40 \%$ of the samples have low durability. These samples water absorption index was ranged from $17.3-28 \% .30 \%$ of the studied rocks have moderate durability and their water absorption index was around 7.7-13.9\%. High durability rock portion was measured about $20 \%$ with water absorption index around 7.04-3.76\%. Only $5 \%$ of the samples remained virtually slightly changed and lays in very high durability category with water absorption less than $3.11 \%$ (sample p-3). A qualitative comparison of the results obtained from the decay indices and indices obtained from Franklin and Chandra [6], Morgenstern and Eigenbrod [29], Gamble [30] and Dick et al [2] classifications show some apparent discrepancies in slake-durability characteristics (Table 6). Above durability classifications indicate that all of samples identified as medium to very high slake-durability. In contrast, the decay index provides a wider range of slake-durability values and shows that approximately $40 \%$ of samples have low durability.

A close inspection of Table 6 shows that in some samples such as P-1, all of the classifications have relatively the same results. This state can be achieved when the materials retained in the $2 \mathrm{~mm}$ mesh drum be relatively sound. In contrast, in most cases (e.g. G-2) difference of rock durability based on
Table 5 New durability classification of clay-bearing rock based on decay index

\begin{tabular}{lcc}
\hline Durability classes & DI ranges & Rock description \\
\hline I & $0-100$ & Very low durable \\
II & $100-500$ & Low durable \\
III & $500-1500$ & Moderately durable \\
IV & $1500-3000$ & High durable \\
V & $>3000$ & Very high durable \\
\hline
\end{tabular}

the classifications is highlighted. This difference shows that the materials retained in the $2 \mathrm{~mm}$ mesh drum consists of disintegrated particles. The same result in durability assessment was achieved by Erguler and Shakoor [15] between disintegration ratio (DR) and durability index (Id). The classification that considers grain size distribution (bigger than $2 \mathrm{~mm}$ ) of slaked material, can truly evaluates durability behavior. The mentioned researcher's classifications did not appear to provide clear distinctions among the slake-durability characteristics of rock samples and may in certain cases provide misleading results. Decay index generally yielded results that better distinguished among the samples. Beside considering grain size distribution and better assessment of durability, the new method has other advantage. As mentioned age, standard test is two cycles durability test with 10 minutes' drum rotation for each cycle. By considering drying time, this method needs about two days' time. Instance, in the proposed method drums were rotated up to 120 minutes' and by considering drying time, the test will be done in a day.

Table 6 Comparison durability of samples tested

\begin{tabular}{|c|c|c|c|c|c|}
\hline SN & Gamble 1971 & Morgenstern and Eigenbrod, 1974 & Franklin and Chandra 1972 & Dick et al. 1994 & This study \\
\hline S-1 & Medium-high & High & High & High & Moderately \\
\hline S-2 & High & High & Very high & High & Moderately \\
\hline S-3 & Medium-high & High & High & High & Low \\
\hline P-1 & High & High & Very high & High & High \\
\hline $\mathrm{P}-2$ & Medium-high & High & High & High & Moderately \\
\hline P-3 & Very high & High & Very high & High & Very high \\
\hline P-4 & Very high & High & Very high & High & High \\
\hline G-1 & Medium-high & High & High & High & Moderately \\
\hline $\mathrm{G}-2$ & very high & High & Very high & High & Low \\
\hline Ag-1 & Medium & High & High & Medium & Low \\
\hline $\mathrm{Ag}-2$ & Medium & High & High & Medium & Low \\
\hline Ag-3 & Medium & High & High & Medium & Low \\
\hline Ag-4 & High & High & Very high & High & Low \\
\hline Ag-5 & Medium & High & High & Medium & Low \\
\hline Ag-6 & Very high & Very high & Very high & High & Moderately \\
\hline $\mathrm{Ag}-7$ & Very high & High & Very high & High & Moderately \\
\hline Ag-8 & Medium-high & High & high & High & Low \\
\hline Ag-9 & Medium-high & High & high & High & Low \\
\hline Ag-10 & Very high & Very high & Very high & High & High \\
\hline Ag-11 & Very high & High & Very high & High & High \\
\hline
\end{tabular}




\subsection{Relationship between decay index and some physical properties}

In this study, a series of statistical analyses were carried out on data from the studied rocks to derive some equations to be used for predicting the durability of these rocks. Regression analyses were also performed to correlate the decay index (DI) values (dependent variable) with different physico-mechanical properties (independent variables) given in Table 2.

Table 7 The best correlations between decay index (DI) and index properties of rock samples

\begin{tabular}{lccc}
\hline Independent variables & Equation & $\mathrm{R}^{2}$ & Type of Eq. \\
\hline $\mathrm{N}$ & $\mathrm{y}=31.277 \mathrm{x}^{-0.511}$ & 0.79 & Power \\
$\mathrm{Iv}$ & $\mathrm{y}=37.9 \mathrm{x}^{-0.6395}$ & 0.96 & Power \\
$\mathrm{Is}_{50}$ & $\mathrm{y}=0.4699 \mathrm{x}^{0.534}$ & 0.76 & Power \\
$\mathrm{CaCO}^{3}$ & $\mathrm{y}=0.7643 \mathrm{x}+32.775$ & 0.55 & Linear \\
\hline
\end{tabular}

Is50: Point load strength index, n: Porosity; Iv: Water absorption index

The purpose was to evaluate that which physico-mechanical properties of clay-bearing rocks influence their disintegration behavior. In the analyses, among the four tested functions (linear, power, non-linear, and exponential), the fitting of power and linear relations to the experimental data yielded higher correlations than those obtained from other relations. Therefore, only power and linear correlations are considered herein. The relationships between the relevant rock properties and decay
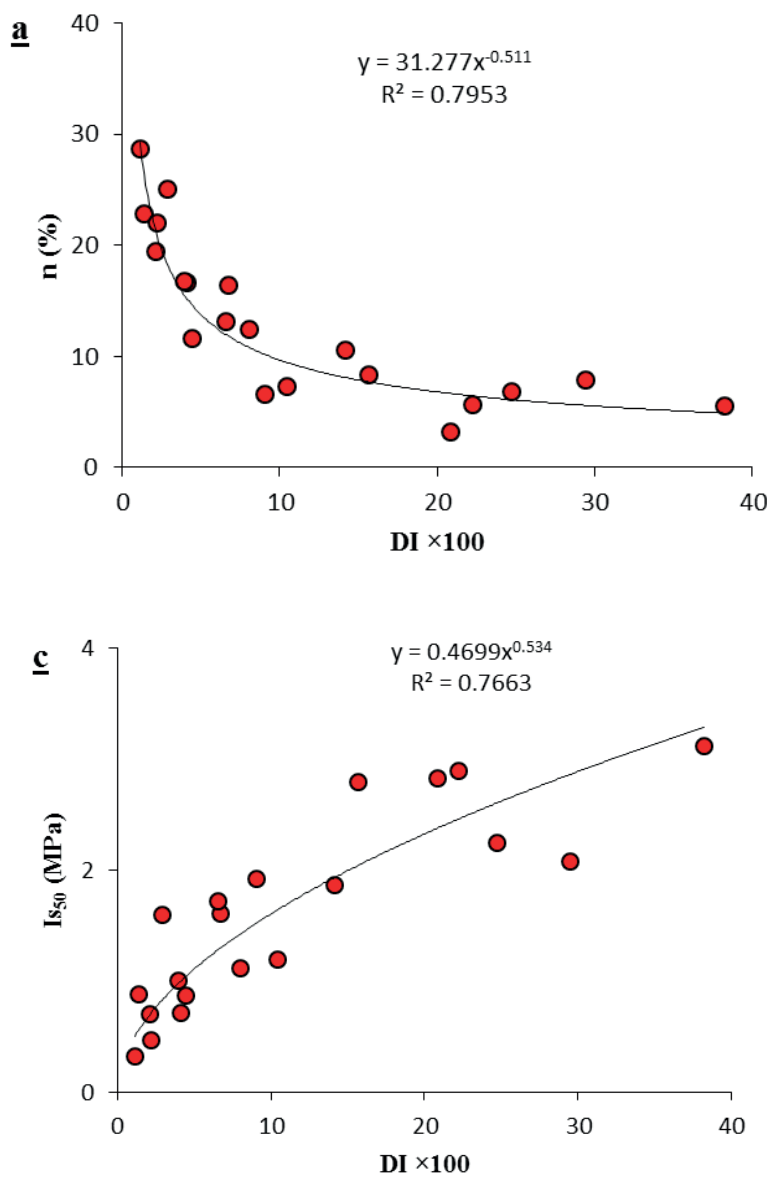

index are given in Fig. 5. The statistical analyses (Table 7) indicated that water absorption, point load strength and porosity show good correlations with DI and will be used as indicator of disintegration behavior of the clay-bearing rocks.

\section{Conclusions}

The primary purpose of this research is to establish practical and simple index that can be used for the better assessment of clay bearing rock slake durability. The results of this study are obtained from of clay-bearing rocks from Iran. Here, quantitative index was used to assess the changes in the slake durability of clay-bearing rocks. The major conclusions of this study are summarized as follows:

- Decay Index, as defined in this research, can be used to describe the slake durability of clay-bearing rocks. The most limitations of the standard test including immersion of samples in water for only $10 \mathrm{~min}$ and assumption fragments larger than $2 \mathrm{~mm}$ as durable materials, were eliminated by the new DI test method.

- According to the results obtained by this study, a new durability classification of clay-bearing rock was proposed in five categories based on DI. The categories of this classification included very high durable (DI > 3000), high durable (DI between 3000-1500), moderately durable (DI between 1500500), low durable (DI between 500-100), and very low durable (DI < 100).
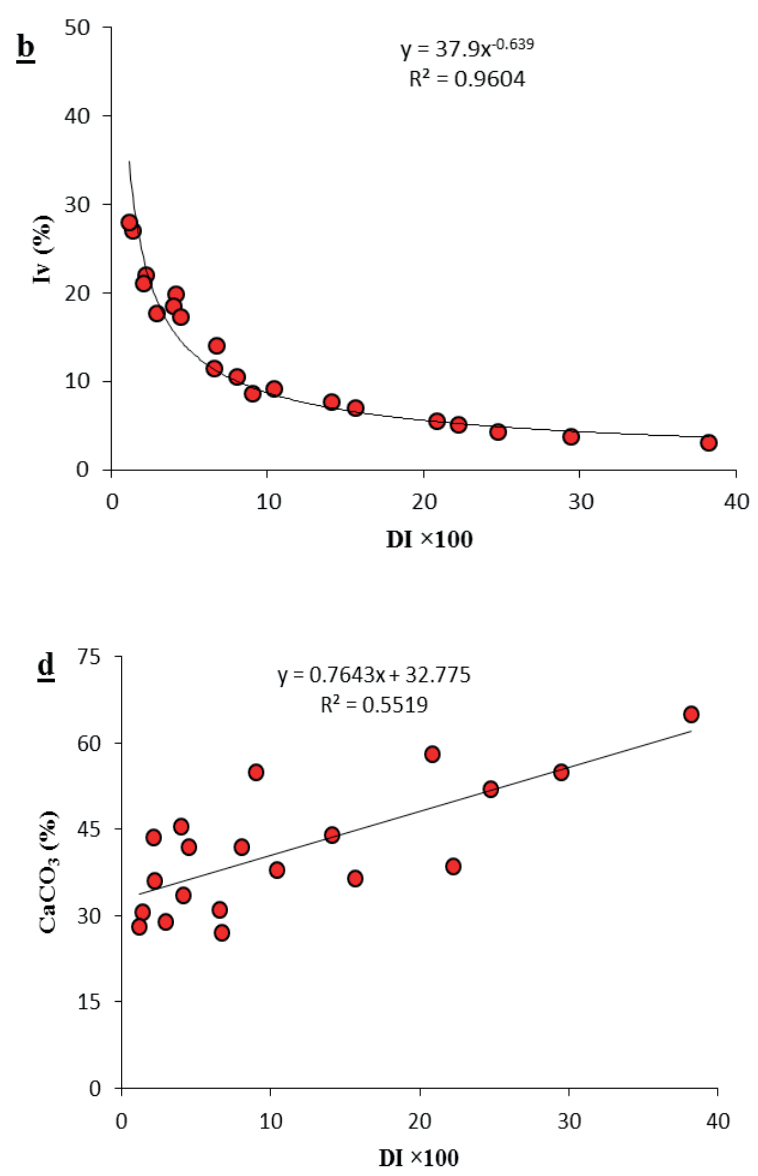

Fig. 5 The relationships between DI and a: porosity, b: water absorption index, c: point load strength, and d: calcium carbonate percentage 
- Comparison of the results obtained from the decay indices and indices obtained from Franklin-Chandra's, Morgenstern and Eigenbrod, Gamble's and Dick et al classifications show discrepancy in evaluation of slake-durability characteristics. Base on the classic durability classification, all of the samples identified as medium to very high slake-durability. In contrast, the decay index provides a wide range of slake-durability values and show that approximately $40 \%$ of samples have low durability.

- Percent water absorption was found as the most important parameter which affects durability behavior of clay-bearing rocks. The obtained equation between this parameter and decay index will be used for prediction of DI.

\section{Acknowledgement}

This work was supported by the Bu-Ali Sina University. The authors are grateful to Dr. B. Rafiei for his assistance during this work.

\section{References}

[1] Franklin, J. A. "Evaluation of shales for construction projects: an Ontario shale rating system. Report RR 229". Research and Development Branch, Ministry of Transportation and Research, Toronto, 1983.

[2] Dick, J. C., Shakoor, A., Wells, N. "Geological approach toward developing a mudrock durability classification system". Canadian Geotechnical Journal, 31 (1), pp. 17-27. 1994. 10.1139/t94-003

[3] Santi, P. M. "Improving the jar slake, slake index, and slake durability tests for shales". Environmental and Engineering Geoscience IV, (3), pp. 385 396. 1998. 10.2113/gseegeosci.IV.3.385

[4] Wood, L. E., Deo, P. “A Suggested System for Classifying Shale Materials for Embankment". Bulletin of Engineering Geology and the Environment, 12 (1), pp. 39-55. 1975.

[5] Deo, P. "Shales as embankment materials", Ph. D. Thesis, Purdue University, December. 1972.

[6] Franklin, J. A., Chandra, A. "The Slake-Durability Test". International Journal of Rock Mechanics and Mining Sciences, 9, pp. 325-341. 1972. 10.1016/0148-9062(72)90001-0

[7] Moon, V. G., Beattie, A. G. "Textural and micro structural influence on the durability of Waikato coal measures mud rocks". Quarterly Journal of Engineering Geology and Hydrogeology, 28, pp. 303-312. 1995. 10.1144/ GSL.QJEGH.1995.028.P3.08

[8] Gokceoglu, C. "The approaches to overcome the difficulties encountered in the engineering classification of clay-bearing, densely jointed and weak rock masses". PhD Thesis, Hacettepe University, Geological Engineering Department (in Turkish). 1997.

[9] Koncagul, E. C. and Santi, P. M. "Predicting the unconfined compressive strength of the Breathitt shale using slake durability, Shore hardness and rock structural properties". International Journal of Rock Mechanics and Mining Sciences, 36(2), pp. 139-153. 1999. 10.1016/S0148-9062(98)00174-0

[10] Sadisun, I. A., Shimada, H., Ichinose, M., Matsui, K., Study on the physical disintegration characteristics of Subang claystone subjected to a modified slaking index test". Geotechnical and Geological Engineering, 23, pp. 199-218. 2005. 10.1007/s10706-003-6112-6

[11] Fuenkajorn, K. "Experimental assessment of long-term durability of some weak rocks". Bulletin of Engineering Geology and the Environment, 70, pp. 203-211. 2011. 10.1007/s10064-010-0297-8

[12] Bryson, L. S., Gomez-Gutierrez, I.C. and Hopkins, T.C. "Development of a New Loss Slake Durability Index for Compacted Shales". Engineering Geology, 139-140, pp. 66-75. 2012. 10.1016/j.enggeo.2012.04.011

[13] Erguler, Z. A., Ulusay, R. "Assessment of physical disintegration characteristics of clay-bearing rocks: disintegration index test and a new durability classification chart". Engineering Geology, 105, pp. 11-19. 2009. 10.1016/j.enggeo.2008.12.013

[14] Taylor, R. K. "Coal measures mudrocks: composition, classification and weathering processes". Quarterly Journal of Engineering Geology and Hydrogeology, 21, pp. 85-99. 1988. 10.1144/GSL.QJEG.1988.021.01.06

[15] Erguler Z. A., Shakoor A. "Relative contribution of various climatic processes in disintegration of clay-bearing rocks". Engineering Geology, 108, pp. 36-42. 2009. 10.1016/j.enggeo.2009.06.002

[16] Gautam, T. P., Shakoor, A. "Slaking behavior of clay-bearing rocks during a one-year exposure to natural climatic conditions". Engineering Geology, 166, pp. 17-25. 2013. 10.1016/j.enggeo.2013.08.003

[17] Gauta, T. P., Shakoor, A. "Comparing the Slaking of Clay-Bearing Rocks under Laboratory Conditions to Slaking Under Natural Climatic Conditions". Rock Mechanics and Rock Engineering, 49 (1), pp. 19-31. 2016.

[8] Rincon, O., Shakoor, A. Ocampo, M. "Investigating the reliability of H/V spectral ratio and image entropy for quantifying the degree of disintegration of weak rocks". Engineering Geology, 207, pp. 115-128. 2016. 10.1016/j. enggeo.2016.04.020

[19] Heidari, M., Rafie, B., Mohebi, Y., Torabi-Kave, M. "Assessing the Behavior of Clay-Bearing Rocks Using Static and Dynamic Slaking Indices". Geotechnical and Geological Engineering, 33 (4), pp. 1017-1030. 2016. 10.1007/s10706-015-9884-6

[20] Nadeesha H. Koralegedara, N. H., Maynard J. B. "Chemical, mineralogical and textural properties of the Kope Formation mudstones: How they affect its durability". Engineering Geology, 228, pp. 312-322. 2017. 10.1016/j. enggeo.2017.08.025

[21] ASTM. Annual Book of ASTM Standards, Soil and Rock, Construction: v. 8, Section 4, West Conshohocken, PA. 950 p. 1996.

[22] ISRM. International Society of Rock Mechanics Commission on Testing Methods, Suggested Method for Determining Point Load Strength, International Journal of Rock Mechanics and Mining Sciences and Geomechanics Abstract 22, pp.51-60. 1985.

[23] ASTM C97-02. Standard Test Methods for Absorption and Bulk Specific Gravity of Dimension Stone. 2004.

[24] Erguler, Z. A., Investigation of the Effect of Water Content on Engineering Behavior of the Clay-Bearing Rocks. PhD Thesis, Hacettepe University, Geological Engineering Department. 2007.

[25] Irfan, T. Y., Dearman, W.R. "Engineering classification and index properties of a weathered granite". Bulletin of the International Association of Engineering Geology, 17, pp. 79-90. 1978. 10.1007/BF02634696

[26] Sousa, L. M. O., Suárezdel Río, L. M., Calleja, L., Ruiz de Argandoña, V., Rey, A. R. "Influence of microfractures and porosity on the physicomechanics properties and weathering of ornamental granites". Engineering Geology, 77, pp.153-168. 2005. 10.1016/j.enggeo.2004.10.001

[27] Ruedrich, J., Kirchner, D., Siegesmund, S., "Physical weathering of building stones induced by freeze thaw action: a laboratory long term study". Environmental Earth Sciences, 63, pp.1573-1586. 2011. 10.1007/s12665010-0826-6

[28] Khanlari, G. R., Heidari, M., Momeni, A. A. "Assessment of weathering processes effect on engineering properties of Alvand granitic rocks (west of Iran), based on weathering indices". Environmental Earth Sciences, 67, pp. 713-725. 2012. 10.1007/s12665-011-1518-6

[29] Morgenstern, N. R. Eigenbrod, K. D, "Classification of argillaceous soils and rocks". Journal of the Geotechnical Engineering Division, ASCE, 100, N. GT10, Proc. Pap. 10885: 1137-1156. 1974.

[30] Gamble, J. C. Durability-Plasticity Classification of shales and other argillaceous rocks. Ph.D. Thesis, University of Illinois, Urabana. 1971. 